\title{
A Helical Ladder Polymer: Synthesis and Magnetic Circular Dichroism of Poly[phenylene-4,6-bis(methylsulfonio)-1,3-diyl triflate]
}

\author{
Tomokazu IwASAKI, Keita KATAYose, Yusaku KoHINATA, and Hiroyuki NishidE ${ }^{\dagger}$ \\ Department of Applied Chemistry, Waseda University, 3-4-1 Ohkubo, Shinjyuku-ku, Tokyo 169-8555, Japan
}

(Received March 16, 2005; Accepted May 6, 2005; Published August 15, 2005)

\begin{abstract}
A helical ladder polymer composed of a fused-benzothiophenium ring was synthesized via the intramolecular ring-closing reaction of the methylsulfoxide-substituted poly(1,3-phenylene). The precursor polymer was prepared by the palladium-catalyzed polymerization of 1,3-dibromobenzene and 1,3-phenylenebisborate and the following quantitative oxidation. The intramolecular ring-closing of the precursor polymer yielded poly[phenylene-4,6bis(methylsulfonio)-1,3-diyl triflate]. The polymer structure did not involve any structural defects based on NMR analysis, which was supported by the model dimers and the control reaction using the monomeric analogues. The obtained polymer is one of the new poly(thiaheterohelicene)s. Magnetic circular dichroism of the polymer suggested an electron transition ascribed to the fused-ring structure. [DOI 10.1295/polymj.37.592]

KEY WORDS $\pi$-Conjugated Polymer / Intramolecular Cyclization / Helical Structure / Helicene /

Sulfonium Salt / Magnetic Circular Dichroism /
\end{abstract}

$\pi$-Conjugated polymers containing a thiophene moiety afford a stable doped state due to an excess $\pi$-electron conjugation and have a high electrical conductivity among the $\pi$-conjugated aromatic polymers. ${ }^{1-4}$ On the other hand, helical polymers have a precisely ordered stereostructure, and they are applied to a chiral separator and a sensor. ${ }^{5-20} \pi$-Conjugated helical molecules consisting of aromatic fused-rings are called "helicenes" and have been often characterized by a unique optical activity caused by their $\pi$ conjugation with helical structure and by a stiff structure derived from the aromatic fused-rings. ${ }^{16-26}$

Among them, the "thiaheterohelicenes" consist of fused-benzothiophene rings, and it has been reported that their helical structure and $\pi$-conjugation are stable under wide conditions such as in an acidic or basic solvent and even at high temperature. ${ }^{27,28}$ The heterohelicene also showed a second-harmonic generation circular dichroism. ${ }^{18}$ Classical methods available for the syntheses of the helicenes and thiaheterohelicenes are the oxidative photo-cyclization of the cis-stilbene $^{29}$ and cis-di(2-thienyl)ethylene derivatives, ${ }^{22,23}$ a reaction of benzoquinone and enol esters, ${ }^{17}$ a Friedel-Crafts reaction of 9,10-phenanthrenes, ${ }^{20}$ and the annulation of thiophene rings using lithium di-isopropylamine. ${ }^{24-26}$ However, these synthetic methods required stepwise synthetic routes, and there have been only a few reports ${ }^{30,31}$ of the thiaheterohelicene with a high molecular weight or a sufficient number of repeating units to form a helical structure.

In this study, we designed a new thiaheterohelicene as the target molecule with a helical $\pi$-conjugated structure and described its synthesis using the intramolecular ring-closing reaction of the sulfonium electrophile to form the fused-ring moiety. We have reported an efficient synthetic route to produce "poly(thiaacene)"s which are comprised of fused sulfurcontaining aromatic rings and have a planar and ladder-type structure. ${ }^{32-35}$ The key step to form the poly(thiaacene)s is the quantitative ring-closing reaction of the alkyl sulfoxide-substituted aromatic polymers. For example, the ring-closing of poly[1,4-phenylene-alt2,5-bis(methylsulfinyl)-1,4-phenylene] yields poly(phenylene-2,5-dithia-1,4-diyl). ${ }^{33}$ This poly(thiaacene) involves the benzothiophene unit that is alternatively linked (or fused) up and down, and gave a significantly developed $\pi$-electron conjugation. We extended this poly(thiaacene), in this paper, to design and provide a high molecular weight thiaheterohelicene, i.e., poly[phenylene-4,6-bis(methylsulfonio)1,3-diyl triflate] (1 in Chart 1).

Magnetic circular dichroism (MCD) is an electronic spectroscopy used to study the induced optical activity caused by an exterior magnetic field and has been applied to magnetically active, or paramagnetic and ferromagnetic, molecules such as heme-protein and -enzyme. ${ }^{36,37} \mathrm{MCD}$ is also effective for estimating the magnetic moments of the ground and excited states of the $\pi$-conjugated cyclic compounds. ${ }^{38}$ In this paper, we applied MCD spectroscopy, for the first time, to the ring-closed polymer and the electron transition based on the molecular structure of poly(thiaheterohelicene).

${ }^{\dagger}$ To whom correspondence should be addressed (Tel: +81-3-3200-2669, Fax: +81-3-3209-5522, E-mail: nishide@ waseda.jp). 


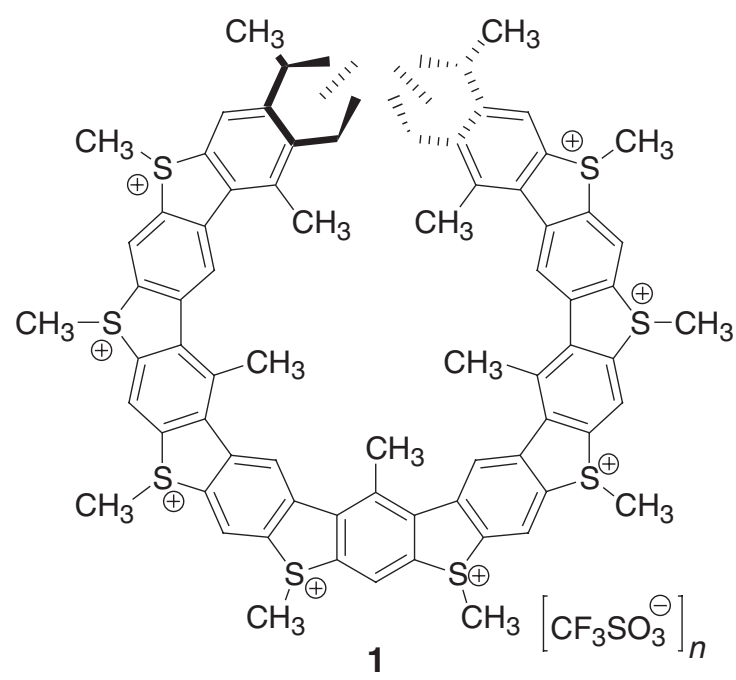

Chart 1.

\section{EXPERIMENTAL}

\section{2-(Methylthio)biphenyl (2)}

2-Bromothioanisole $(4.06 \mathrm{~g}, 20 \mathrm{mmol})$ and phenylboronic acid $(2.44 \mathrm{~g}, 20 \mathrm{mmol})$ were dissolved in THF $(200 \mathrm{~mL})$ under argon. Tetrakis(triphenylphosphine)palladium (0) $(1.27 \mathrm{~g}, 1.1 \mathrm{mmol})$ and a $2 \mathrm{M}$ aqueous sodium carbonate solution $(100 \mathrm{~mL})$ were added to the solution, and the mixture was stirred at $70^{\circ} \mathrm{C}$ under argon for $18 \mathrm{~h}$. The mixture was cooled to room temperature, the organic phase was extracted with diethyl ether and then washed with water. After drying over anhydrous sodium sulfate followed by evaporation, the residue was purified by silica gel column chromatography with the hexane and chloroform $(\mathrm{v} / \mathrm{v}=2 / 1)$ mixture as the eluent to give a white powder: yield $96 \% ;{ }^{1} \mathrm{H} \mathrm{NMR}\left(\mathrm{CDCl}_{3}, 500 \mathrm{MHz}\right): \delta$ $7.64(\mathrm{~d}, 2 \mathrm{H}), 7.61(\mathrm{t}, 2 \mathrm{H}), 7.54(\mathrm{t}, 1 \mathrm{H}), 7.49(\mathrm{t}, 1 \mathrm{H})$, $7.45(\mathrm{~d}, 1 \mathrm{H}), 7.41(\mathrm{~d}, 1 \mathrm{H}), 7.36(\mathrm{t}, 1 \mathrm{H}), 2.49(\mathrm{~s}$, $3 \mathrm{H}) .{ }^{13} \mathrm{C} \mathrm{NMR}\left(\mathrm{CDCl}_{3}, 125 \mathrm{MHz}\right): \delta 140.7,140.3$, $137.0,129.8,129.1,127.9,127.7,127.3,125.0$, 124.5, 15.6; IR $\left(\mathrm{KBr}, \mathrm{cm}^{-1}\right): 2923\left(v_{\mathrm{C}-\mathrm{H}}\right) ; \mathrm{MS}$ $(\mathrm{m} / \mathrm{z}): 200\left(\mathbf{M}^{+}\right)$, calcd for $\mathbf{M}=200.3$; Anal. Calcd for $\mathrm{C}_{13} \mathrm{H}_{12} \mathrm{~S}$ : C, 78.0; H, 6.0. Found: C, 77.6; H, 5.4.

\section{2-(Methylsulfinyl)biphenyl (3)}

A dichloromethane $(200 \mathrm{~mL})$ solution of $2(2.67 \mathrm{~g}$, $13.3 \mathrm{mmol})$ was stirred at $30^{\circ} \mathrm{C}$. A $30 \%$ aqueous hydroxyperoxide solution $(53.2 \mathrm{~mL})$ and acetic acid $(13.3 \mathrm{~mL})$ were added to the solution, and the mixture was stirred at $30^{\circ} \mathrm{C}$ for $4 \mathrm{~h}$. The organic phase was extracted with chloroform and washed with water. The solution was dried over anhydrous sodium sulfate and concentrated, the residue was purified by silica gel column chromatography with the chloroform and methanol $(\mathrm{v} / \mathrm{v}=5 / 1)$ mixture as the eluent to give a white powder: yield $97 \%$; ${ }^{1} \mathrm{H}$ NMR $\left(\mathrm{CDCl}_{3}, 500\right.$ $\mathrm{MHz}): \delta 8.13$ (d, 1H), 7.63 (t, 1H), 7.54 (t, 1H), 7.48$7.41(\mathrm{~m}, 3 \mathrm{H}), 7.38(\mathrm{~d}, 2 \mathrm{H}), 7.33(\mathrm{~d}, 1 \mathrm{H}), 2.36(\mathrm{~s}, 3 \mathrm{H})$. ${ }^{13} \mathrm{C} \mathrm{NMR}\left(\mathrm{CDCl}_{3}, 125 \mathrm{MHz}\right): \delta 140.7,140.3,136.9$, 129.8, 129.1, 127.9, 127.7, 127.3, 125.0, 124.5, 41.5; IR $\left(\mathrm{KBr}, \mathrm{cm}^{-1}\right): 2925\left(v_{\mathrm{C}-\mathrm{H}}\right), 1047\left(v_{\mathrm{S}=\mathrm{O}}\right) ; \mathrm{MS}(\mathrm{m} / z)$ : $216\left(\mathrm{M}^{+}\right)$, calcd for $\mathrm{M}=216.3$; Anal. Calcd for $\mathrm{C}_{13} \mathrm{H}_{12} \mathrm{OS}$ : C, 72.2; H, 5.6. Found: C, 72.5; H, 5.5.

\section{5-Methyldibenzothiophenium triflate (4)}

$3(108 \mathrm{mg}, 0.5 \mathrm{mmol})$ was added to triflic acid $(10 \mathrm{~mL})$, and the solution was stirred at room temperature for $72 \mathrm{~h}$ in the dark. The mixture was poured into diethyl ether $(300 \mathrm{~mL})$ and a white solid was precipitated. The precipitation was filtered and dried under vacuum to give the sulfonium salts 3: yield 98\%; ${ }^{1} \mathrm{H}$ NMR $\left(\mathrm{CD}_{3} \mathrm{CN}, 500 \mathrm{MHz}\right): \delta 8.24(\mathrm{~m}, 4 \mathrm{H}), 7.86$ $(\mathrm{t}, 2 \mathrm{H}), 7.72(\mathrm{t}, 2 \mathrm{H}), 3.32(\mathrm{~s}, 3 \mathrm{H}) .\left(\mathrm{CF}_{3} \mathrm{SO}_{3} \mathrm{D}, 500\right.$ MHz): $\delta 7.33$ (d, 2H), 7.15 (d, 2H), 7.01 (t, 2H), 6.85, $(\mathrm{t}, 2 \mathrm{H}), 2.36$ (s, 3H). ${ }^{13} \mathrm{C}$ NMR $\left(\mathrm{CD}_{3} \mathrm{CN}, 125 \mathrm{MHz}\right): \delta$ $140.2,134.9,132.0,131.7,128.7,125.2,35.1$; IR $\left(\mathrm{KBr}, \mathrm{cm}^{-1}\right): 2917\left(v_{\mathrm{C}-\mathrm{H}}\right), 1256\left(v_{\mathrm{C}-\mathrm{F}}\right), 1165\left(v_{\mathrm{SO}_{2}}\right)$; ESI-MS (m/z): $198\left(\mathrm{M}^{+}\right)$, calcd for $\mathrm{M}-\mathrm{CF}_{3} \mathrm{SO}_{3}{ }^{-}=$ 199.3; Anal. Calcd for $\mathrm{C}_{14} \mathrm{H}_{11} \mathrm{~F}_{3} \mathrm{O}_{3} \mathrm{~S}_{2}$ : C, 48.3; H, 3.2. Found: C, 48.0; H, 3.4.

Poly[4,6-bis(methylthio)-1,3-phenylene-alt-2-methyl1,3-phenylene] (7) (Table I, run 6)

$5 \quad(172.0 \mathrm{mg}, \quad 0.50 \mathrm{mmol}), \quad 1,5$-dibromo-2,5-bis(methylthio)benzene (6) $(164.0 \mathrm{mg}, 0.50 \mathrm{mmol})$, tetrakis(triphenylphosphine)palladium(0) (11.6 mg, 0.010 $\mathrm{mmol})$ and THF $(5.0 \mathrm{~mL})$ were placed in a $10 \mathrm{~mL}$ ampoule in a glove box under argon. After the addition of a $2.0 \mathrm{M}$ aqueous sodium carbonate solution $(1.0 \mathrm{~mL})$, the ampoule was evacuated, sealed, and heated at $80^{\circ} \mathrm{C}$ for $72 \mathrm{~h}$. The reaction mixture was dropwise poured into $200 \mathrm{~mL}$ of methanol, and the precipitate was filtered and then washed with methanol and hot water. The precipitate was dissolved in chloroform then reprecipitated in $200 \mathrm{~mL}$ of hexane. The precipitate was dried under vacuum to give a white powder: yield $97 \% ;{ }^{1} \mathrm{H} \mathrm{NMR}\left(\mathrm{CD}_{2} \mathrm{Cl}_{2}, 500 \mathrm{MHz}\right): \delta 7.31-6.92$ $(\mathrm{m}, 5 \mathrm{H}), 2.45(\mathrm{~s}, 6 \mathrm{H}), 1.91(\mathrm{~s}, 3 \mathrm{H}) .{ }^{13} \mathrm{C}$ NMR $\left(\mathrm{CD}_{2}-\right.$ $\left.\mathrm{Cl}_{2}, 125 \mathrm{MHz}\right): \delta 154.9,138.3,133.1,132.1,126.2$, 122.0, 117.7, 114.5, 15.7, 12.6; IR (KBr, $\left.\mathrm{cm}^{-1}\right): 2949$ $\left(v_{\mathrm{C}-\mathrm{H}}\right)$; GPC $\left(\mathrm{CHCl}_{3}\right.$, PSt calibration): $M_{\mathrm{n}}=7500$, $M_{\mathrm{w}}=10500 \quad\left(M_{\mathrm{w}} / M_{\mathrm{n}}=1.4\right) ; \quad$ Anal. Calcd for $\mathrm{C}_{15} \mathrm{H}_{14} \mathrm{~S}_{2}$ : C, 69.7; H, 5.5. Found: C, 69.5; H, 5.3.

Poly[4,6-bis(methylsulfinyl)-1,3-phenylene-alt-2-methyl-1,3-phenylene] (8)

A dichloromethane $(4 \mathrm{~mL})$ solution of $7(51.7 \mathrm{mg}$, 0.20 unit $\mathrm{mmol}$ ), a $30 \%$ aqueous hydrogen peroxide solution $(0.8 \mathrm{~mL})$, and acetic acid $(0.4 \mathrm{~mL})$ were stirred at $30^{\circ} \mathrm{C}$ for $10 \mathrm{~h}$. The organic phase was extracted 
with chloroform, and washed with water. After drying and evaporation, the residue was dissolved in $0.5 \mathrm{~mL}$ of chloroform and precipitated in hexane. The precipitate was dried under vacuum to give a white powder: yield $92 \%$; ${ }^{1} \mathrm{H}$ NMR $\left(\mathrm{CD}_{2} \mathrm{Cl}_{2}, 500 \mathrm{MHz}\right): \delta 8.78(\mathrm{~s}$, $1 \mathrm{H}), 7.56-7.15(\mathrm{~m}, 4 \mathrm{H}), 2.59(\mathrm{~s}, 6 \mathrm{H}), 1.98$ (s, 3H); IR $\left(\mathrm{KBr}, \mathrm{cm}^{-1}\right)$ : $2960\left(v_{\mathrm{C}-\mathrm{H}}\right), 1050\left(v_{\mathrm{S}=\mathrm{O}}\right)$; Anal. Calcd for $\mathrm{C}_{15} \mathrm{H}_{14} \mathrm{O}_{2} \mathrm{~S}_{2}$ : C, 62.0; H, 4.9. Found: C, 61.6; H, 5.3.

Poly[phenylene-4,6-bis(methylsulfonio)-1,3-diyl triflate] (1)

8 (100 mg, 0.34 unit mmol) was dissolved in triflic acid $(6.8 \mathrm{~mL})$. The solution stirred at room temperature for $7 \mathrm{~d}$ and poured into diethyl ether $(100 \mathrm{~mL})$. The precipitate was washed with diethyl ether and water, then dried under vacuum to give a light brown powder: yield: $98 \% ;{ }^{1} \mathrm{H} \mathrm{NMR}\left(\mathrm{CF}_{3} \mathrm{SO}_{3} \mathrm{D}, 500 \mathrm{MHz}\right)$ : $\delta 8.48(\mathrm{~s}, 1 \mathrm{H}), 7.22(\mathrm{~s}, 1 \mathrm{H}), 7.05(\mathrm{~s}, 1 \mathrm{H}), 2.99(\mathrm{~s}, 6 \mathrm{H})$, $1.72(\mathrm{~s}, 3 \mathrm{H})$; IR $\left(\mathrm{KBr}, \mathrm{cm}^{-1}\right): 2917\left(v_{\mathrm{C}-\mathrm{H}}\right), 1256$ $\left(v_{\mathrm{C}-\mathrm{F}}\right), 1165\left(\delta_{\mathrm{SO}_{2}}\right)$; Anal. Calcd for $\mathrm{C}_{17} \mathrm{H}_{12} \mathrm{~F}_{6} \mathrm{O}_{6} \mathrm{~S}_{4}$ : C, 36.8; H, 2.2. Found: C, 37.0; H, 2.5.

\section{Materials}

All reagents were obtained from the Kanto Chemical Co., Tokyo Kasei Co. and Aldrich Chemical Co., and used without further purification. 2-Methyl-1,3phenylenebis(pinacol borate) (5) and 1,5-dibromo2,4-bis(methylthio)benzene (6) were prepared according to a previous paper. ${ }^{31}$

\section{Measurements}

The ${ }^{1} \mathrm{H}$ and ${ }^{13} \mathrm{C}$ NMR, mass, and infrared spectra were recorded on a JEOL Lambda 500, a Shimadzu GCMS-QP5050, and a JASCO FT/IR-410 spectrometer, respectively. The elemental analysis was performed on a Perkin-Elmer PE-2400 and a Metrohm 645 Multi DOSIMAT. The UV-vis MCD were measured on a JASCO V-550 and J-820/MCD-414.

\section{For the ${ }^{1} H$ NMR Study of the Intramolecular Ring- closing}

An inner NMR tube $(\phi 2 \mathrm{~mm})$ was filled with acetone- $d 6$ containing $0.1 \%$ TMS as the standard, and placed in the center of an outer standard NMR tube $(\phi 5 \mathrm{~mm})$ which was filled with the $\mathrm{CF}_{3} \mathrm{SO}_{3} \mathrm{D}(0.5$ $\mathrm{mL})$ solution of $\mathbf{3}(5.4 \mathrm{mg}, 0.025 \mathrm{mmol})$.

\section{RESULTS AND DISCUSSION}

\section{Synthesis and Characterization of Model Dimers}

The model dimers were synthesized to study the coupling reaction that forms polymer 1 (Chart 1). 2(Methylthio)biphenyl (2) was prepared by the palladium-catalyzed coupling reaction of 2-bromothioanisole

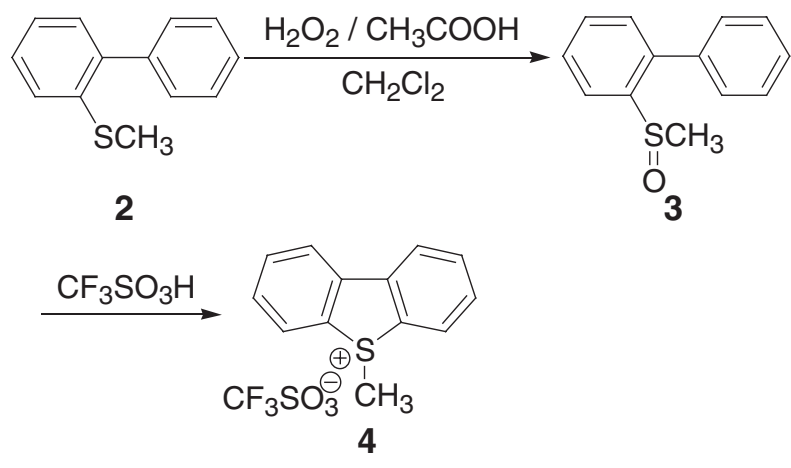

Scheme 1.

and phenylboronic acid. The coupling of an equivalent amount of the couplers almost quantitatively gave $\mathbf{2}$ (see Experimental Part) to support that the palladium-catalyzed coupling is effective for the precursor polymer formation. The pendant methyl sulfide of $\mathbf{2}$ was quantitatively oxidized with peracetic acid at $30^{\circ} \mathrm{C}$ to yield 3 . The following intramolecular ringclosing of $\mathbf{3}$ afforded 5-methyldibenzothiophenium triflate (4). The ${ }^{13} \mathrm{C}$ NMR spectrum of $\mathbf{4}$ showed six signals in the aromatic region which were ascribed to the fused-ring molecular structure of $\mathbf{4}$ (see Experimental Part). The strong IR absorption bands attributed to the $\mathrm{C}-\mathrm{F}$ and $\mathrm{SO}_{2}$ stretching vibrations of the counter triflate anion at $1256\left(v_{\mathrm{C}-\mathrm{F}}\right)$ and $1165\left(v_{\mathrm{SO}_{2}}\right)$ $\mathrm{cm}^{-1}$ supported the sulfonio/triflate salt formation.

The ring closing reaction, i.e., the fused-ring formation was monitored by ${ }^{1} \mathrm{H} \mathrm{NMR}$ on the $\mathrm{CF}_{3} \mathrm{SO}_{3} \mathrm{D}$ solution of 3 (Figure 1). During the initial period, the signals of $\mathbf{3}(\delta 7.18,6.98,6.91,6.70$, and $6.45 \mathrm{ppm})$ disappeared and those of $4(\delta 7.33,7.15$, 7.01 , and $6.85 \mathrm{ppm})^{34,39}$ appeared. After $3 \mathrm{~d}$, the reaction was completed and no other peaks ascribed to a by-product (except for water) and side-reaction were detected during the reaction. These results indicated that the analogous reaction forms the corresponding fused-ring polymer without any structural defects.

Synthesis of the Precursor Polymer, Poly[4,6-bis(methylthio)-1,3-phenylene-alt-2-methyl-1,3-phenylene]

The precursor polymer, poly[4,6-bis(methylthio)1,3-phenylene-alt-2-methyl-1,3-phenylene] (7), was prepared as shown in Scheme 2, by the following molecular design: Polycondensation of 2-methyl-1,3phenylenebis(pinacol borate) (5) and 1,5-dibromo-2,4bis(methylthio)benzene (6) leads to both a high molecular weight precursor polymer and the introduction of two alkylthio groups at the favorable positions of the precursor for the following ring formation reaction.

2-Methyl-1,3-phenylenebis(pinacol borate) (5) was prepared by the Grignard reaction of 2,6-dibromotoluene with pinacol borate. ${ }^{31}$ On the basis of the reaction conditions obtained through the model dimer 
Poly[phenylene-4,6-bis(methylsulfonio)-1,3-diyl triflate]

Table I. Conditions and results of polymerization of $\mathbf{5}$ and $\mathbf{6}^{\mathrm{a}}$

\begin{tabular}{|c|c|c|c|c|c|c|c|c|}
\hline \multirow[t]{2}{*}{ No. } & $\begin{array}{l}\text { Monomer } \\
\text { concn }\end{array}$ & \multirow{2}{*}[\mathrm{Pd}]{$/\left[\mathrm{M}_{0}\right]$} & Base aq. ${ }^{c} / \mathrm{THF}$ & $\begin{array}{c}\text { Reaction } \\
\text { time }\end{array}$ & Yield & $M_{\mathrm{n}}{ }^{\mathrm{d}}$ & \multirow{2}{*}{$M_{\mathrm{w}} / M_{\mathrm{n}}$} & \multirow{2}{*}{$\begin{array}{c}\text { Degree of } \\
\text { polymn }\end{array}$} \\
\hline & $\mathrm{M}^{\mathrm{b}}$ & & $\mathrm{v} / \mathrm{v}$ & $\mathrm{h}$ & $\%$ & $10^{3}$ & & \\
\hline 1 & 0.1 & $1 / 20$ & $1 / 2$ & 72 & 96 & 2.9 & 1.6 & 22 \\
\hline 2 & 0.1 & $1 / 50$ & $1 / 2$ & 72 & 91 & 4.6 & 1.6 & 36 \\
\hline 3 & 0.1 & $1 / 100$ & $1 / 2$ & 72 & 95 & 2.6 & 1.4 & 20 \\
\hline 4 & 0.1 & $1 / 50$ & $1 / 5$ & 24 & 95 & 3.4 & 1.5 & 26 \\
\hline 5 & 0.1 & $1 / 50$ & $1 / 5$ & 48 & 98 & 4.4 & 1.8 & 34 \\
\hline 6 & 0.1 & $1 / 50$ & $1 / 5$ & 72 & 97 & 7.5 & 1.4 & 58 \\
\hline 7 & 0.2 & $1 / 50$ & $1 / 5$ & 72 & 73 & 2.2 & 1.2 & 17 \\
\hline 8 & 0.2 & $1 / 50$ & $1 / 5$ & 72 & 95 & 2.9 & 1.2 & 22 \\
\hline 9 & 0.2 & $1 / 50$ & $1 / 5$ & 72 & 98 & 3.6 & 1.6 & 28 \\
\hline
\end{tabular}

${ }^{\mathrm{a}}$ Reaction Temp. $=80{ }^{\circ} \mathrm{C}$. Pd cat. $=\mathrm{Pd}\left(\mathrm{PPh}_{3}\right)_{4} \cdot{ }^{\mathrm{b}}$ The THF solution. ${ }^{\mathrm{c}} 2 \mathrm{M}$ aqueous $\mathrm{Na}_{2} \mathrm{CO}_{3}$ solution. ${ }^{\mathrm{d}}$ Number- and weight-average molecular weight measured by GPC.

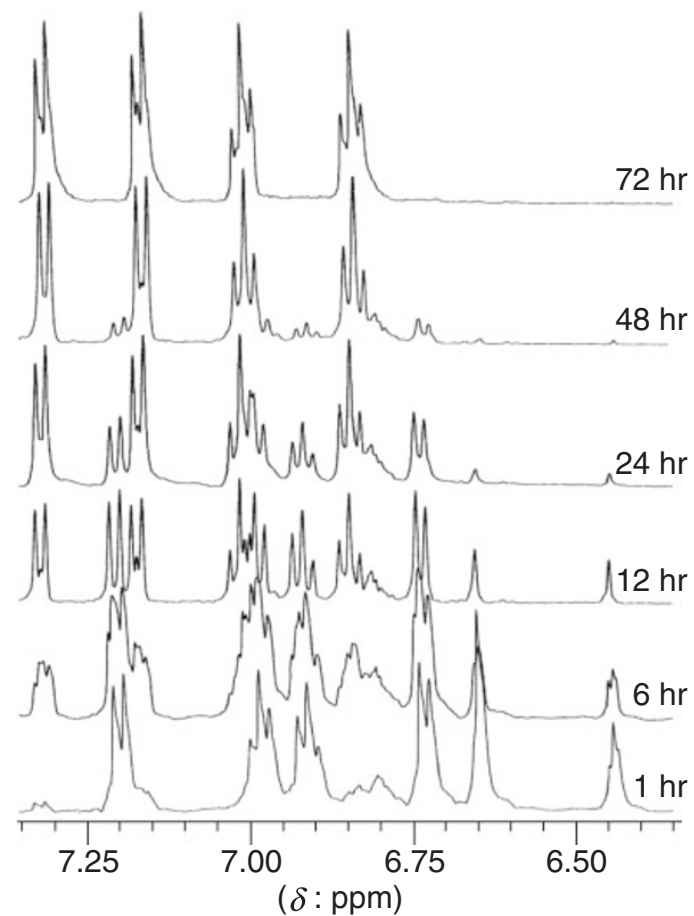

Figure 1. ${ }^{1} \mathrm{H}$ NMR spectra (monitoring the aromatic region) of the ring-closing reaction of $\mathbf{3}$ in $\mathrm{CF}_{3} \mathrm{SO}_{3} \mathrm{D}$ at $30^{\circ} \mathrm{C}$.

synthesis, 5 and 1,5-dibromo-4,6-bis(methylthio)benzene $(\mathbf{6})^{31}$ were polymerized with tetrakis(triphenylphosphine)palladium(0) as a catalyst and sodium carbonate as a base in a THF and water mixture at $80^{\circ} \mathrm{C}$ (Scheme 2). The polymerization conditions and results are shown in Table I.

The polymerization conditions were optimized for the monomer and catalyst concentration, the feed amount of the aqueous base solution and the reaction time. The obtained white-yellow polymer was soluble in the common solvents such as dichloromethane, toluene, and THF. The ${ }^{13} \mathrm{C}$ NMR spectrum gave eight signals in aromatic region that are consistent with the precise 1,3-linking phenylene unit structure of 7 (see<smiles>Cc1c(B2OC(C)(C)C(C)(C)O2)cccc1B1OC(C)(C)C(C)(C)O1</smiles>

5

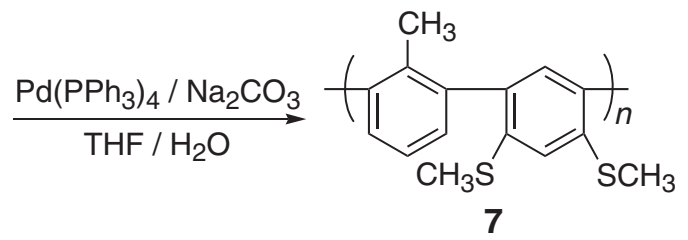

Scheme 2.

Experimental Part). The highest number averaged molecular weight was 7500 (degree of polymerization $=$ 58 based on the phenylene ring, Table I, run 6) which satisfies a helical ladder structure with 8-9 pitches. (ca. 1 helical pitch $=7$ phenylene units in $\mathbf{1}^{21}$ ).

Ring Closing Reaction to Form the Helical Ladder Polymer Comprised of Fused-benzothiophene Ring

The pendant sulfide of $\mathbf{7}$ was oxidized with hydroxy peroxide and acetic acid at $30{ }^{\circ} \mathrm{C}$ using the optimized reaction temperature and time (see Experimental Part). The sulfoxide-substituted polymer, poly[4,6bis(methylsulfinyl)-1,3-phenlene-alt-2-methyl-1,3-phenylene] (8), gave the ${ }^{1} \mathrm{H}$ NMR signal at $2.59 \mathrm{ppm}$ as a symmetrical singlet which was shifted from that of $\mathbf{7}$ $(2.45 \mathrm{ppm})$ due to the electron withdrawing nature of the sulfoxide. All signals ascribed to the methylsulfide and methyl-sulfone group disappeared, which indicated that all the pendant sulfide groups were converted to the sulfoxide. The IR spectrum showed the peak of the strong $\mathrm{S}=\mathrm{O}$ stretch band at $1050 \mathrm{~cm}^{-1}$.

The precursor polymer (8) was reacted with triflic acid for 1 week (Scheme 3). To avoid the intermole- 


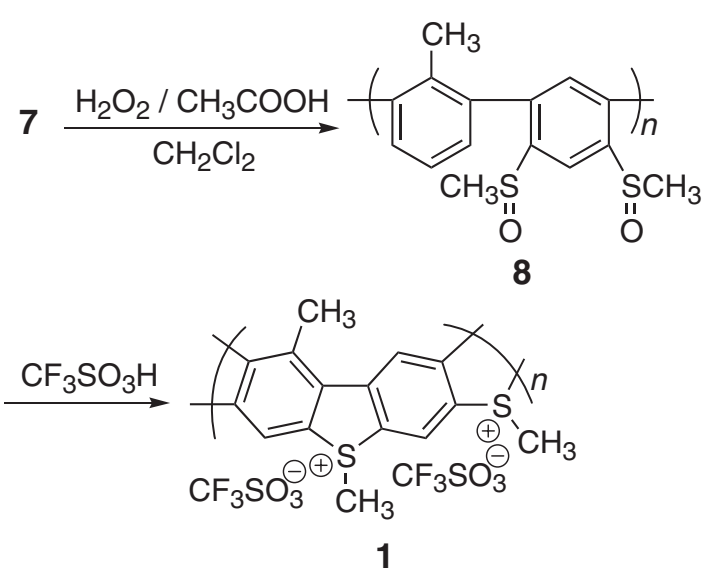

Scheme 3.
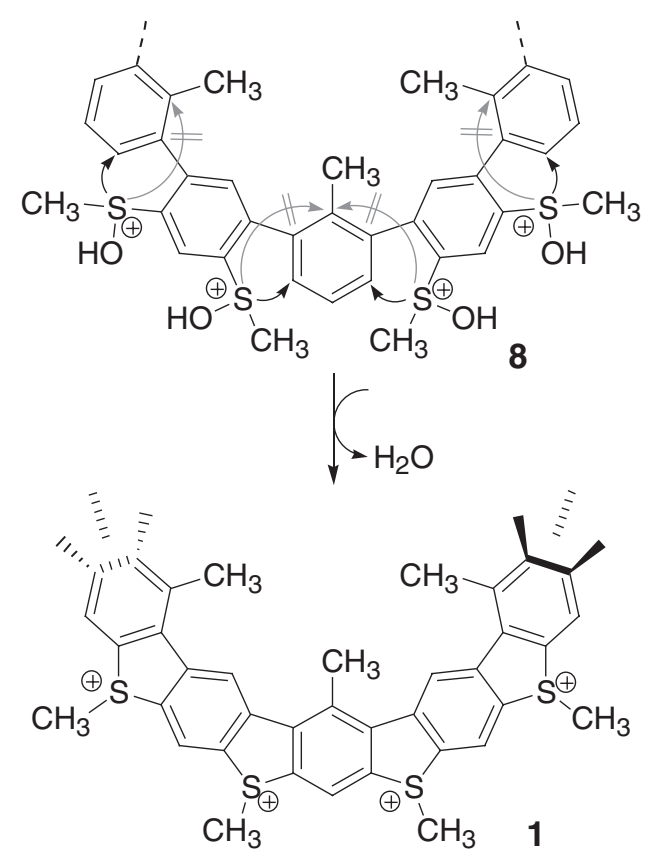

Scheme 4.

cular electrophilic reaction of sulfonium cation, the ring-closing reaction was carried out in highly diluted solution. The obtained polymer was soluble in DMF, DMSO, and a protonic acid, such as trifluoroacetic acid and triflic acid. The 2-methyl group of the phenylene ring in $\mathbf{8}$ resulted in the selective intramolecular and electrophilic attack of the pendant sulfoxides on the favored 4 and 6 positions of their neighboring phenylene ring (Scheme 4).

The ${ }^{1} \mathrm{H}$ NMR spectrum of the polymer in $\mathrm{CF}_{3} \mathrm{SO}_{3} \mathrm{D}$ is shown in Figure 2. ${ }^{40}$ The fused-ring structure of $\mathbf{1}$ was proved by the signal of the methyl group adjacent to the sulfur atoms which shifted to the lower magnetic field $(\delta 2.99 \mathrm{ppm})$ from that of the precursor sulfoxide $(\delta 2.59 \mathrm{ppm})$. The integral values of the protons derived from the phenyl ring $(3 \mathrm{H})$, the aryl methyl group $(3 \mathrm{H})$, and the methyl group on the sulfonio

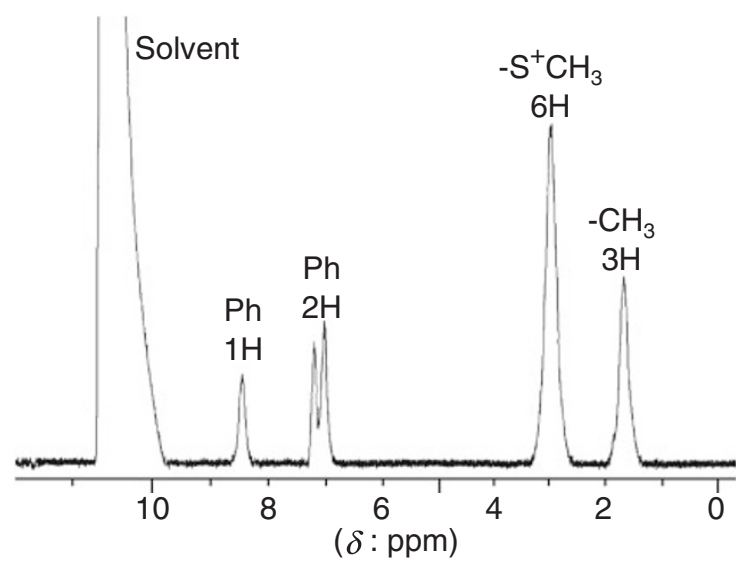

Figure 2. ${ }^{1} \mathrm{H}$ NMR spectrum of $\mathbf{1}$ in $\mathrm{CF}_{3} \mathrm{SO}_{3} \mathrm{D}$.

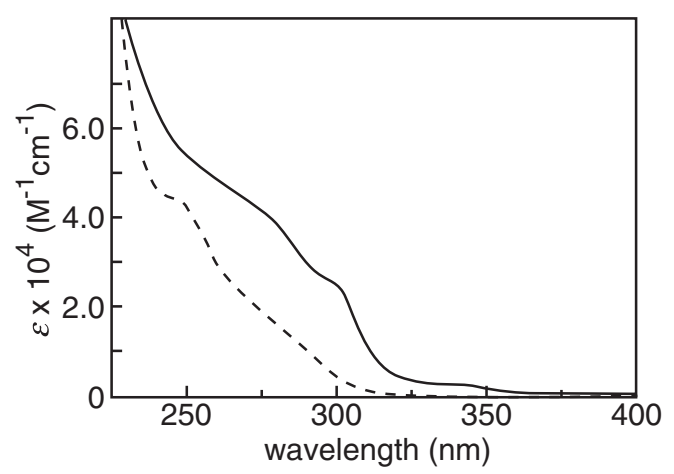

Figure 3. UV-vis spectra of $\mathbf{1}$ (solid line) and $\mathbf{8}$ (dotted line) in $0.1 \mathrm{mM}$ DMF solution.

bridges $(4 \mathrm{H})$ also supported the repeating unit structure of $1 .{ }^{31}$ The results indicated that the ring-closing reaction of the alkylsulfinyl-substituted poly(1,3phenylene) could form the helical structure without the helical conformation of precursor. ${ }^{31}$

\section{$U V$-vis and MCD Spectra}

The UV-vis absorption spectra of $\mathbf{8}$ and $\mathbf{1}$ are shown in Figure $3 .{ }^{41}$ The absorption maxima $\left(\lambda_{\max }\right)$ of $\mathbf{1}$ at 278, 307, and $342 \mathrm{~nm}$ and the shoulder at $375 \mathrm{~nm}$ shifted from those of $\mathbf{8}\left(\lambda_{\max }=251 \mathrm{~nm}\right.$, shoulder $=320 \mathrm{~nm}$ ), suggesting an extension of the $\pi$-conjugation in the ladder structure of $\mathbf{1}$. 1 was not circular dichroism (CD) active because its helical conformation was racemic. ${ }^{31}$ The racemic structure was favorable for the following magnetic circular dichroism (MCD) measurement.

MCD was used to analyze the electron transition in the fused-ring structure. The MCD was measured for the model dimers ( 3 and 4 ) in $0.1 \mathrm{mM}$ acetonitrile solution and the polymers (8 and $\mathbf{1}$ ) in DMF solution under a magnetic field of $1.5 \mathrm{~T}$. All the compounds showed symmetrical profiles in the MCD spectra during the measurements under positive and negative magnetic fields, ${ }^{42}$ and the following discussion was 


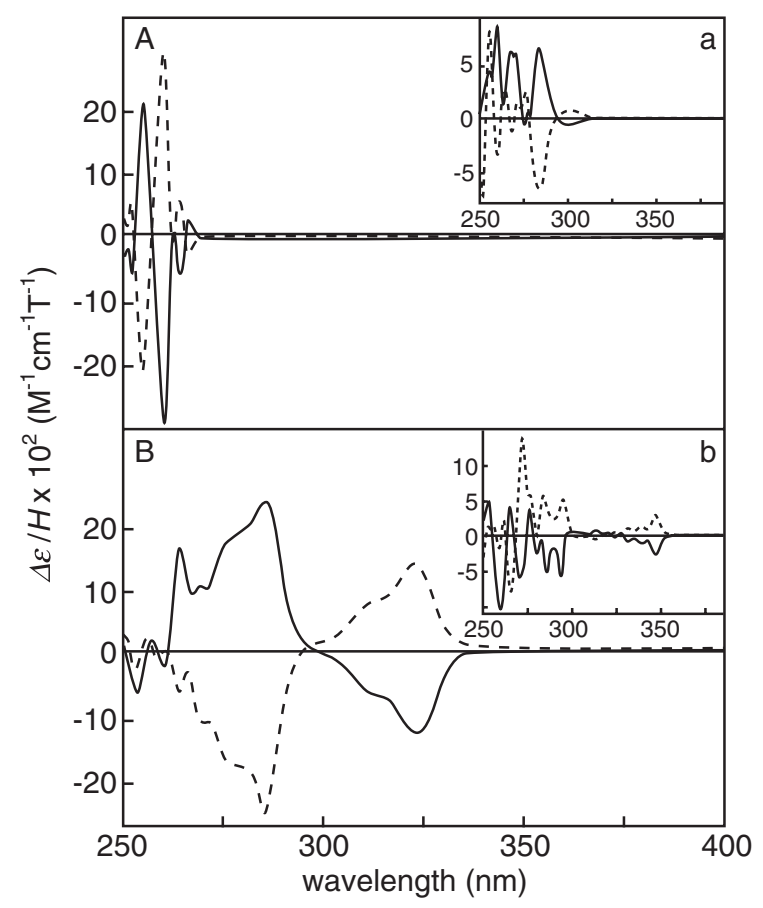

Figure 4. MCD spectra of 3 (A), 4 (B), $m$-terphenyl (a), and phenanthrene (b) under positive (solid line) and negative (dotted line) magnetic fields.

carried out using the spectra under the positive magnetic field.

The MCD of 3 showed a peak at $259 \mathrm{~nm}$ on the negative side which was ascribed to the $\pi-\pi^{*}$ transition of the biphenyl moiety (Figure 4 ). 4 had peaks in not only the $\pi-\pi^{*}$ transition range ${ }^{41}(261-298 \mathrm{~nm}$, positive) but also at 310 and $325 \mathrm{~nm}$ in the negative side. We measured the MCD of $m$-terphenyl $\left(\left[1,1^{\prime} ; 3^{\prime}, 1^{\prime \prime}\right]\right.$ terphenyl) and phenanthrene, which are unfused and fused cyclic compounds, respectively, as the control experiments (Figure 4, inset). ${ }^{38,43}$ The peaks of $m$-terphenyl at 270 and $280 \mathrm{~nm}$ on the positive side and those of phenanthrene at 285 and $294 \mathrm{~nm}$ on the negative side had been ascribed to a singlet electron $\left(S_{0}-S_{1}\right)$ transition of the fused-ring. ${ }^{38}$ Other peaks were observed on the negative side at 328, 337 and 349 $\mathrm{nm}$ for phenanthrene, but not $m$-terphenyl; they had been attributed to a $\mathrm{S}_{0}-\mathrm{S}_{2}$ transition based on the fused-ring. ${ }^{38,43}$ That is, the peaks observed for $\mathbf{4}$ at 310 and $325 \mathrm{~nm}$ could be assigned to the $\mathrm{S}_{0}-\mathrm{S}_{2}$ transition which was based on the fused-ring of $\mathbf{4}$.

Based on these results, the MCD of the polymers 8 and $\mathbf{1}$ was studied (Figure 5). The precursor polymer $\mathbf{8}$ showed positive peaks at 264,270 , and $275 \mathrm{~nm}$ in the $\pi-\pi^{*}$ transition region. The negative peaks appeared in the range of $276-328 \mathrm{~nm}$. On the other hand, the ring-closed polymer 1 exhibited broad peaks at 286, 317 , and $343 \mathrm{~nm}$ (positive, negative, and positive, respectively), and the peaks corresponded to the absorption maxima of $\mathbf{1}$ in Figure 3. These results

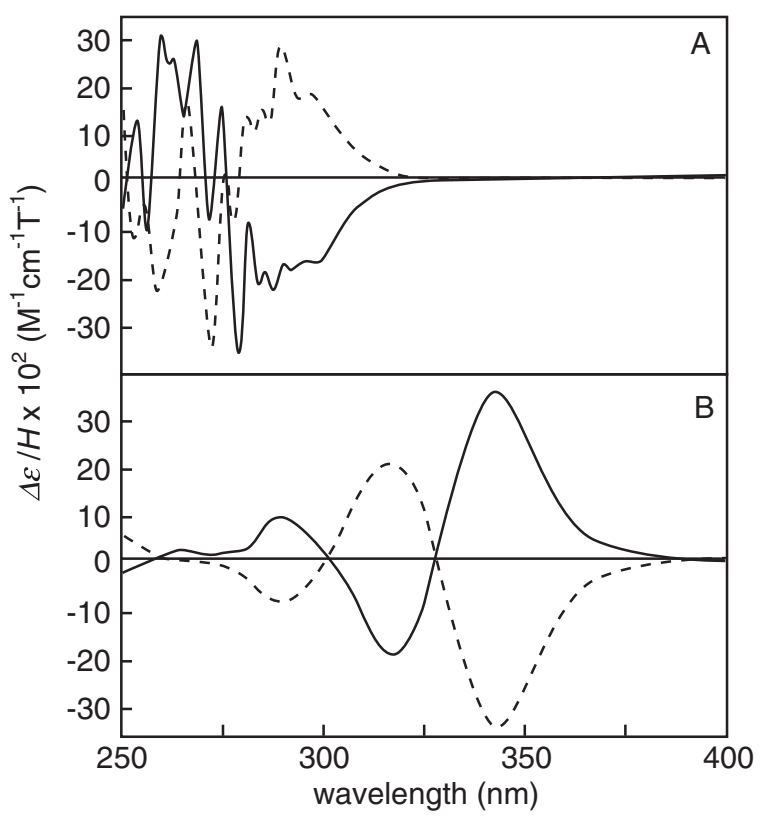

Figure 5. MCD spectra of $\mathbf{8}(\mathrm{A}), \mathbf{1}$ (B) under positive (solid line) and negative (dotted line) magnetic fields.

indicated that the MCD peaks of $\mathbf{1}$ at 286 and $317 \mathrm{~nm}$ were ascribed to the $\pi-\pi^{*}$ transition and that at $343 \mathrm{~nm}$ is to the intrinsic electron transition of the fused-ring structure. ${ }^{44}$

In summary, a novel helical ladder polymer comprised of fused-benzothiophenium rings, poly(thiaheterohelicene), was synthesized via the intramolecular ring-closing reaction of the methyl-sulfoxidesubstituted poly(1,3-phenylene). The MCD spectroscopy indicated that the peaks based on the fused-ring appeared in the range of the intrinsic electron transition generated by the formation of the ladder structure. We have already simulated the electronic conduction of poly(thiaheterohelicene) from the view point of a molecular-based electronic device. ${ }^{45}$ This simulation suggested not only an electron transmittance along the helical $\pi$-conjugation under a lower bias voltage (around the Fermi level of $\mathrm{Au}$ ), but also a solenoid-like induced magnetism; such a poly(thiaheterohelicene) is a potential candidate for studying the one-dimensional wire of an organic molecularbased electromagnet.

Acknowledgment. This work was partially supported by Grant-in-Aids for the Scientific Research and the COE Program "Practical Nano-Chemistry" from MEXT, Japan.

\section{REFERENCES}

1. T. Yamamoto, D. Komarudin, M. Arai, B.-L. Lee, H. Suganuma, N. Asakawa, Y. Inoue, K. Kubota, S. Sasaki, T. Fukuda, and H. Matsuda, J. Am. Chem. Soc., 120, 2047 
(1998)

2. J. Roncali, Chem. Rev., 92, 711 (1992).

3. T. Yamamoto, M. Arai, H. Kokubo, and S. Sasaki, Macromolecules, 36, 7986 (2003).

4. K. Oyaizu, T. Iwasaki, Y. Tsukahara, and E. Tsuchida, Macromolecules, 37, 1257 (2004).

5. T. Nakano and Y. Okamoto, Chem. Rev., 101, 4013 (2001).

6. C. Yamamoto, E. Yashima, and Y. Okamoto, J. Am. Chem. Soc., 124, 12583 (2002).

7. E. Yashima, K. Maeda, and Y. Okamoto, Nature 399, 449 (1999).

8. E. Yashima, K. Maeda, and T. Nishimura, Chem.-Eur. J., 10, 42 (2004)

9. K. Maeda, K. Morino, Y. Okamoto, T. Sato, and E. Yashima, J. Am. Chem. Soc., 126, 4329 (2004).

10. M. M. Green, J.-W. Park, T. Sato, A. Teramoto, S. Lifson, R. L. B. Selinger, and J. V. Selinger, Angew. Chem. Int. Ed., 38, 3138 (1999).

11. M. M. Green, K.-S. Cheon, S.-Y. Yang, J.-W. Park, S. Swansburg, and W. Liu, Acc. Chem. Res., 34, 672 (2001).

12. M. Fujiki, J. R. Koe, M. Motonaga, H. Nakashima, K. Terao, and A. Teramoto, J. Am. Chem. Soc., 123, 6253 (2001).

13. H. Nakashima, M. Fujiki, J. R. Koe, and M. Motonaga, J. Am. Chem. Soc., 123, 1963 (2001).

14. K. Akagi, G. Piao, S. Kaneko, K. Sakamaki, H. Shirakawa, and M. Kyotani, Science, 282, 1683 (1998).

15. D. J. Hill, M. J. Mio, R. B. Prince, T. S. Hughes, and J. S. Moore, Chem. Rev., 101, 3893 (2001).

16. T. Verbiest, S. V. Elshocht, M. Kaouranen, L. Hellemans, J. Snauwaert, C. Nuckolls, T. J. Katz, and A. Persoons, Science, 282, 913 (1998).

17. J. M. Fox, N. R. Goldberg, and T. J. Katz, J. Org. Chem., 63, 7456 (1998).

18. S. Sioncke, S. V. Elshocht, T. Verbiest, M. Kauranen, K. E. S. Phillips, T. J. Katz, and A. Persoons, Synth. Met., 124, 191 (2001).

19. T. Verbiest, S. Sioncke, A. Persoons, L. Vyklický, and T. J. Katz, Angew. Chem. Int. Ed., 41, 3882 (2002).

20. K. Paruch, T. J. Katz, C. Incarvito, K.-C. Lam, B. Rhatigan, and A. L. Rheingold, J. Org. Chem., 65, 7602 (2000).

21. K. Tanaka, H. Suzuki, and H. Osuga, J. Org. Chem., 62, 4465 (1997).

22. T. Caronna, T. Sinisi, M. Catellani, L. Malpezzi, S. V. Meille, and A. Mele, Chem. Commun., 13, 1139 (2000).

23. T. Caronna, M. Catellani, S. Luzzati, L. Malpezzi, S. V. Meille, C. Ritchter, and R. Sinisi, Chem. Mater., 13, 3906 (2001).

24. A. Rajca, H. Wang, M. Pink, and S. Rajca, Angew. Chem. Int. Ed., 39, 4481 (2002).

25. A. Rajca, M. Miyasaka, M. Pink, H. Wang, and S. Rajca,
J. Am. Chem. Soc., 126, 15211 (2004).

26. M. Miyasaka, A. Rajca, M. Pink, and S. Rajca, Chem.-Eur. J., 10, 6531 (2004).

27. H. Wynberg, Acc. Chem. Res., 4, 65 (1971).

28. K. Yamada, H. Nakagawa, and H. Kawazura, Bull. Chem. Soc. Jpn., 59, 2429 (1971)

29. F. B. Malloy and C. W. Malloy, "Organic Reactions," Vol. 30, Wiley Interscience, New York, N.Y., 1984, p 1.

30. T. Iwasaki, Y. Tsukahara, and H. Nishide, Chem. Lett., 34, 164 (2005).

31. T. Iwasaki, Y. Kohinata, and H. Nishide, Org. Lett., 7, 755 (2005).

32. K. Yamamoto, E. Shouji, H. Nishide, and E. Tsuchida, J. Am. Chem. Soc., 115, 5819 (1993).

33. A. Haryono, K. Miyatake, J. Natori, and E. Tsuchida, Macromolecules, 32, 3146 (1999).

34. K. Oyaizu, T. Mikami, F. Mitsuhashi, and E. Tsuchida, Macromolecules, 35, 67 (2002).

35. E. Tsuchida and K. Oyaizu, Bull. Chem. Soc. Jpn., 76, 15 (2003).

36. A. D. Buckingham and P. J. Stephens, Annu. Rev. Phys. Chem., 17, 399 (1966).

37. P. N. Schatz and A. J. McCafery, Q. Rev. Chem. Soc., 23, 552 (1969).

38. M. Vasak, M. Whipple, and J. Michl, J. Am. Chem. Soc., 100, 6867 (1978).

39. The chemical shift of 4 in $\mathrm{CF}_{3} \mathrm{SO}_{3} \mathrm{D}$ was different from the one in $\mathrm{CD}_{3} \mathrm{CN}$ due to the deuteration on the phenylene rings in $\mathrm{CF}_{3} \mathrm{SO}_{3} \mathrm{D}$ (protonation in $\mathrm{CF}_{3} \mathrm{SO}_{3} \mathrm{H}$ ). The details had been reported in ref 34 .

40. $\mathrm{CF}_{3} \mathrm{SO}_{3} \mathrm{D}$ was selected as the solvent for the ${ }^{1} \mathrm{H}$ NMR study since the signals of the methyl groups adjacent to the sulfur atoms and a solvent, such as DMF- $d_{7}(2.74,2.91$, and $8.01 \mathrm{ppm})$ and DMSO- $d_{6}(2.50 \mathrm{ppm})$, overlapped.

41. The absorption spectra of $\mathbf{3}$ and $\mathbf{4}$ had been reported in ref 33 .

42. Slight unsymmetrical profiles measured at the positive and negative magnetic fields in Figures 4 and 5 was caused by the apparatus setup. When the direction of the magnetic field (from $\mathrm{N}$ to $\mathrm{S}$ pole) is parallel to one of the circular polarized irradiation, the magnetic field is called "positive".

43. T. Dahlgren, J. Glans, S. Gronowitz, A. Davidsson, B. Norden, P. B. Pedersen, and E. W. Thulstrup, Chem. Phys., 40, 397 (1979).

44. The actual method to analyze the MCD spectrum for polymers is very complicated due to the molecular weight distribution and the variety of conformations, and has not yet been established.

45. K. Tagami, M. Tsukada, Y. Wada, T. Iwasaki, and H. Nishide, J. Chem. Phys., 119, 7491 (2003). 